\title{
MORFOLOGIA E COBERTURA DETRÍTICA DA PLATAFORMA LITORAL NA ÁREA DE ALBERGARIA-A-VELHA (DISTRITO DE AVEIRO).
}

\author{
António Alberto Gomes ${ }^{1}$; ANTÓNio BARRA ${ }^{2}$
}

Resumo

Abstract

\begin{abstract}
A plataforma litoral na área de Albergaria-a-Velha revela características morfológicas curiosas: as notórias superfícies aplanadas extensas e regulares contrastam vincadamente, com as vertentes íngremes e rigidamente orientadas dos sectores deprimidos que a seccionam meridianamente.

Para além dos contrastes morfológicos também se encontram vários tipos de cobertura sedimentar que correspondem a diferentes episódios de deposição, balizados pela instalação da rede hidrográfica actual. As coberturas mais antigas (Pliocénico/Quaternário inferior) parecem relacionar-se com outro sistema lididrográfico, hoje desaparecido.

A passagem neste sector de um dos tramos da falha Porto-Tomar, com a direç̧ão N/S assume un papel primordial na definição do relevo da área.

$\mathrm{O}$ aparente basculamento das superficies aplanadas e respectivas coberturas, algumas particularidades no traçado da rede hidrográfica e a existência de vigorosas escarpas de falha nítidas, levam-nos a concluir que terão ocorrido movimentações recentes ao longo dos acidentes tectónicos principais.
\end{abstract}

Palavras-chave: Morfologia, plataforma litoral, depósitos de cobertura, cartografia geológica, rede fluvial, neotectónica, Quaternário.

Morphology and sedimentary cover of the littoral platform in the "Albergaria-a-Velha" area (Aveiro district) - The littoral platform of «Albergaria-a-Velha» near Aveiro region has particular morphological features. The flatness of its surface contrasts with the steep slops of its Eastern border.

This slopes have strong relation with the tectonic settings of this area, were it is possible to follow their expression over the landscape, not only the Porto-Tomar Fault, but also other secondary faults. Toward East of the eastern border of the platform of «Albergaria-a-Velha», the relief has deep tectonic valleys, separating its different sectors.

The age of sedimentary cover of the platform is interpreted as Pliocene to Lower Quaternary and is intersected by the actual hydrographical net, which left several terrace deposits.

The tilt shown by some of this surfaces and related deposits, the steepness of some scarps and the hydrographical features leads to the conclusion that the principal tectonic elements of this area have recent movements.

Key words: Morphology, littoral platform, sediments, geological mapping, fluvial network, neotectonic, Quaternary.

\section{INTRODUÇĀO}

Os dados que se apresentam resultam do trabalho de campo empreendido durante o Verão de 2001, no sector ocidental da carta 175 , à escala $1 / 25000$ (figura 1). O objectivo principal foi o reconhecimento dos depósitos de cobertura, com o intuito de iniciar um trabalho mais amplo de compreensão da evolução geomorfológica da plataforma litoral entre Espinho e Águeda.

De entre os trabalhos mais importantes já efectuados neste trecho do Baixo-Vouga destacamos CARVALHO $(1949,1950,1951,1953 a, b)$ que definiu os principais elementos da morfologia da região e efectuou, à luz dos critérios de classificação sedimentológica da época, a caracterização dos depósitos de cobertura, bem como, a sua provável génese.

Mais tarde, FERREIRA (1978) dedica, na sua tese de doutoramento, algumas páginas ao rebordo litoral das montanhas ocidentais da Beira, onde se inclui a plataforma litoral estudada. Estabelece então as interpretações morfológicas mais significativas desta área, que mantemos no essencial, particularmente no que se refere à separação das diferentes unidades morfológicas e ao papel que a tectónica assumiu na estruturação do relevo e da rede hidrográfica.

Numa perspectiva diferente, de índole mais geológica, nomeadamente na componente estrutural e petrológica do substrato pré-paleozoico salientam-se dois autores: os trabalhos de GONÇALVES (1974, 1981), em que o autor define uma cronologia relativa entre os granitóides e o encaixante metassedimentar Precâmbrico, onde publica uma cartografia geológica da área à escala 1/80 000, e mais recente, o trabalho de CHAMINÉ (2000), que publica uma cartografia geológica revista, à escala $1 / 100000$, onde se expressam os dados que resultam da análise pormenorizada da estratigrafia, dos aspectos estruturais e suas implicações geodinâmicas do soco polimetamórfico entre Espinho e Albergaria-a-Velha. 


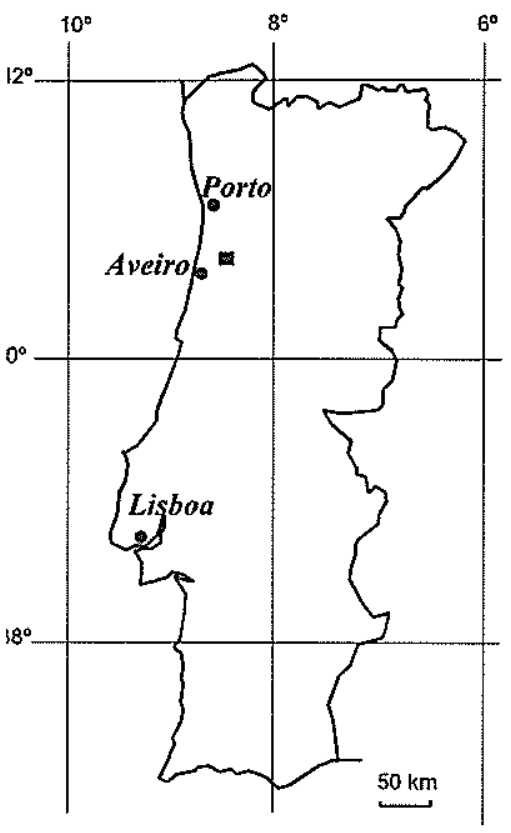

Fig.l - Localização da área estudada. Fig.1 - Studied area localization.

\section{ANÁLISE GEOMORFOLÓGICA}

\subsection{Dados morfológicos}

Em termos de análise morfológica da área diferenciam-se quatro sectores (figura 3 ):

1 - Sector ocidental da Plataforma Litoral que compreende a superficie aplanada a oeste dos vales dos rios Caima e Vouga (as Plataformas das Albergarias, CARVALHO, 1950).

No retalho estudado, esta plataforma consiste numa superfície aplanada que vai subindo gradualmente, desde os 120 até aos 200 metros, terminando contra um alinhamento de pequenas elevações alongadas com a direcção N/S, de Fradelos à Sr. ${ }^{a}$ do Socorro $(216 \mathrm{~m})$. A sul desta pequena elevação, é a própria plataforma que representa o topo do interflúvio ocidental dos rios Caima e Vouga.

Em geral, a plataforma de Albergaria é uma superfície inclinada para Oeste, em direcção ao mar. No entanto, a sul da Sr. do Socorro o declive é mais forte para Sudoeste, no sentido do vale do Vouga, conforme é denunciado pela mudança na orientação da rede hidrográfica (Ribeira de Albergaria-a-Velha e seus afluentes da margem esquerda).

II - Corredor deprimido interior que se estabelece entre as vertentes ocidentais dos vales dos rios Caima/Vouga e a escarpa vigorosa, rectilínea e rigidamente orientada, segundo a direcção N/S que existe a Este, desde Ribeira de Fráguas até Soutelo.
Este corredor corresponde a uma área mais baixa que a anterior, muito escavada pela rede hidrográfica dos rios Caima/Vouga, e dentro da qual se isolam algumas elevações de topo aplanado e vertentes íngremes (Carvalhal, Rendo, Póvoa), e pequenas depressões que se definem no fundo destes vales (Ribeira de Fráguas, Valmaior, Mouquim, Jafafe e Soutelo).

Todo este sector apresenta duas tendências muito vincadas: um basculamento para Este, como já notou FERREIRA (1978), evidenciado pela diminuição da altitude do topo das elevações até atingirem o sopé da abrupta escarpa que as limita; uma diminuição de altitude das superfícies aplanadas, à medida que caminhamos para sul, quer os topos de elevações, quer as bases das depressões. Isto pode comprovar-se pelo facto da cota mais baixa (24 metros) do sector se registar no fundo da depressão de Soutelo, no extremo sul da área.

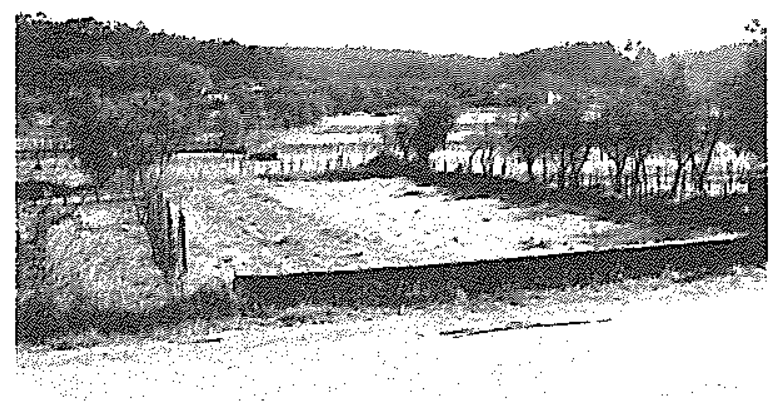

Fig. 2 - Depressão do Soutelo vista para sul. Fig. 2 -South seeing over Soutelo depression.

As pequenas depressões que se abrem no fundo destes vales assumem formas distintas. São por vezes estreitas e alongadas, de fundo plano e limitadas por vertentes rectilíneas, abruptas e orientadas segundo a direcção N/S (depressão de Ribeiro de Fráguas -Bosturenga). Noutros casos apresentam uma forma mais irregular, ampla e com vincado fecho do vale a jusante e montante como acontece em Valmaior. Um terceiro tipo corresponde a uma forma mais aberta e regular, de fundo muito aplanado e limitada por vertentes abruptas e alinhadas, como em Soutelo (fig.2).

III - Retalhos orientais aplanados da Plataforma Litoral, situados acima dos 100 metros de altitude e individualizados pelo activo encaixe da rede hidrográfica.

A conservação do topo aplanado nestes retalhos, contrasta vivamente com os acentuados encaixes da rede hidrográfica que actualmente os degrada (casos da Ribeira da Alombada, Ribeiro do Beco e do próprio Vouga). Estes topos aplanados e de contorno irregular 
são bruscamente interrompidos a leste por escarpas vigorosas e rigidamente alinhadas. A norte do Vouga, as escarpas tomam uma orientação NW/SE, como sucede na rechã de Vila Nova de Fusos, enquanto que a sul do Vouga, a sua direcção inflecte ligeiramente para NNW/SSE, em Alombada e Moita.

IV-Colinas interiores, progressivamente mais altas para leste e que contrastam com as superficies aplanadas situadas a oeste, definindo também elas, alinhamentos muito nítidos, N/S, NNW/SSE e NE/SW.

$\mathrm{O}$ relevo acidentado do interior é composto por uma série de elevações estreitas e alongadas, com topos aplanados muito exíguos e vertentes muito ingremes, fortemente dissecadas pela rede hidrográfica, ela própria assumindo direç̧ões preferenciais, nomeadamente, NE/SW.

\subsection{Dados geológicos}

O reconhecimento geológico da cobertura sedimentar foi o nosso objectivo principal, dado que não está publicada a carta geológica da área (escala 1/50 000), e os dados publicados no trabalho de CHAMINÉ (2000), à escala $1 / 100000$, não coincidem totalmente com o que fomos observando no campo, particularmente, nos sectores mais meridionais.

\subsubsection{Substrato antigo}

O bedrock é composto por rochas metamórficas antigas, pré-paleozoicas e paleozóicas (CHAMiné, 2000). Em termos de grandes domínios morfestrututurais do soco hercínico, nesta área estão representadas duas das zonas definidas para o contexto peninsular por DALlMEyer \& MARTINEZ-GARCIA (1990).

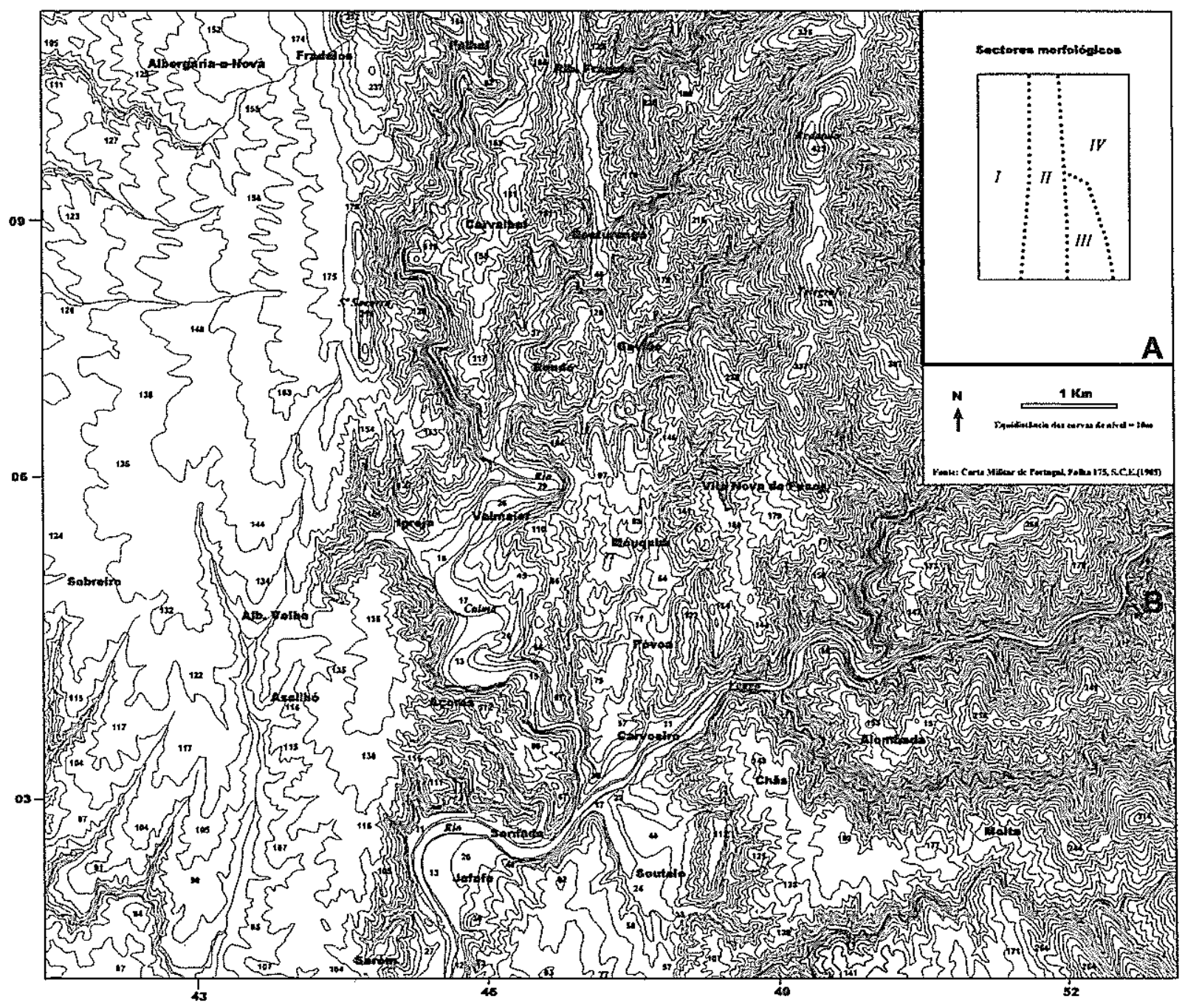

Fig. 3-Altimetria e rede hidrográfica principal.

Fig. 3 - Altimetry and hydrographic network of the studied area. 
A Zona Ossa-Morena incluiu formações antigas do Paleozóico inferior e/ou Precâmbrico, nomeadamente: - a Unidade de Arada, constituída por filádios negros e verdes com níveis de liditos, xistos anfibolíticos e anfibolitos; - a Unidade de São João de Ver composta por micaxistos, por vezes granatíferos, metagrauvaques e anfibolitos, metapórfiros e gnaisses.

$\mathrm{Na}$ área central da carta, a norte de Valmaior a Unidade de Arada é carreada pela Unidade de S. João de Ver (Chaminé, 2000; GonÇAlves, 1974).

A Zona Centro-Ibérica está representada por rochas metamórficas paleozóicas pertencentes ao Complexo Xisto-Grauváquico e ao Ordovícico inferior a médio, a saber: - quartzitos maciços do Arenigiano com xistos cinzentos intercalados; - a Unidade de Carvoeiro-Caldas de São Jorge, que inclui xistos cinzentos ardosiferos, com niveis fossilíferos.

A ocupar pequenas faixas estreitas com eixo N/S e correspondendo a algumas áreas deprimidas topograficamente, desde Ribeira de Fráguas a Mouquim, existe um estreito afloramento da Unidade de Carvoeiro-Caldas de S. Jorge.

Merece também destaque a presença de bancadas de quartzito «Armoricano», verticalizadas e alinhadas segundo a direcção N/S, que se impõem na paisagem pela formação de cristas quartzíticas de vertentes abruptas, e pelo encaixe vigoroso que alguns cursos de água produzem sempre que as tentan vencer (caso do Vouga e dos afluentes orientais da Ribeira de Fráguas). Curioso e para já sem explicação plausível, é o facto do afloramento quartzítico desaparecer bruscamente na margem sul do Vouga.

A Oeste dos afloramentos quartzíticos e ainda pertencente à zona Centro-Ibérica, o soco fortemente dissecado pela rede hidrográfica é constituido pelas litologias típicas do Complexo Xisto-Grauváquico Ante-Ordovícico.

$\mathrm{Na}$ margem esquerda do rio Vouga, a sul de Jafafe, encontra-se uma estreita faixa ocupada por uma formação detrítica triássica - Os Arenitos de Eirol (TEIXEIRA \& ZBYSEWSK1, 1976). Nesta faixa, os arenitos apresentam-se muito bem estratificados $e$ inclinados para Sudeste, com camadas de cor avermelhada, compostas por fragmentos muito angulosos de uma grande variedade de rochas e minerais. Embalados na matriz é possivel distinguir cristais de feldspato pouco alterado e são visíveis bolas de granito podre. Para efeitos deste estudo os Arenitos de Eirol são considerados substrato.

É patente na figura 6 que todo este substrato se encontra muito afectado por movimento tectónicos, particularmente o sector deprimido interior. Esta intensa fracturação é justificada pela presença da Falha Porto-Tomar, uma das mais importantes falhas da Península Ibérica, assumida como uma sutura tectónica muito antiga e com manifestos rejogos posteri- ores, como é evidenciado na Carta da Neotectónica de Portugal de Cabral \& Ribeiro (1988).

Nesta área, a principal direcção de fracturação é efectivamente a direcção N/S que corresponde à da Falha Porto-Tomar. Porém também são representativas as direcções NE/SW, NNE/SSW e NNW/SSE.

\subsubsection{Depósitos de cobertura}

Os depósitos de cobertura podem ser divididos em dois conjuntos: o Conjunto I, aparentemente relacionado com um dispositivo hidrográfico já desaparecido, e o Conjunto II, em íntima relação com a rede hidrográfica actual.

\section{Conjunto I}

Este conjunto, na generalidade, é formado por depósitos de cobertura heterométricos, de cor acastanhada ou amarelo torrada e constituição areno-conglomerática, com pouca matriz e abundantes clastos baços de quartzo e quartzito (Fig. 4). Os clastos

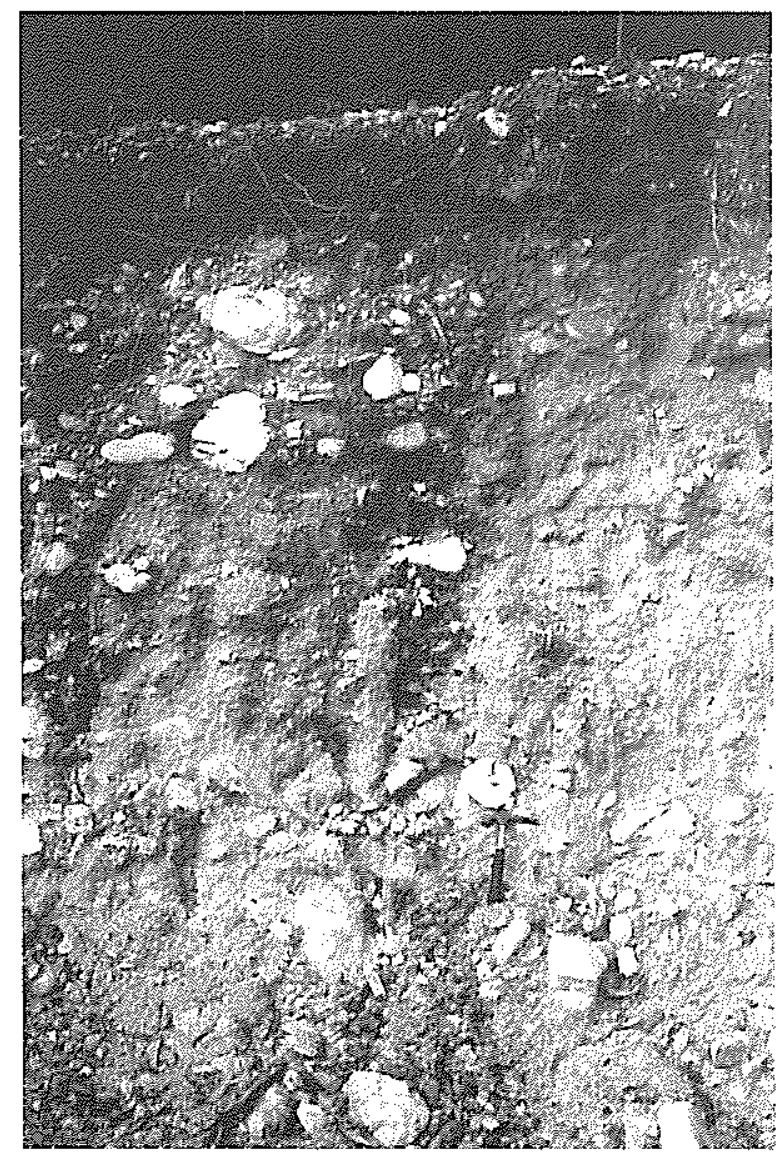

Fig. 4-Depósito conglomerático que constitui uma pequéna elevação no fundo da depressão de Soutelo.

Fig. 4 - Conglomeratic deposit that formed a little hill on Soutelo's depression. 
são arredondados a subarredondados e apresentam frequentemente marcas de choque, podendo alguns blocos ter até 1 metro de eixo maior.

$\mathrm{Na}$ extensa plataforma de Albergaria estes depósitos heterométricos formam coberturas peliculares. No entanto, quando nos aproximamos das elevações (Fradelos-Sr.' do Socorro) que interrompem a Leste, esta plataforma, passamos a encontrar depósitos com cores mais claras e constituição francamente arenosa, compostos por seixos esbranquiçados e arredondados de quartzo e quartzito. Surgem, por vezes, intercalações de níveis esbranquiçados, silto-argilosos ricos em matriz, essencialmente micácea. No topo destes depósitos é possivel observar couraças ferruginosas de pequena espessura $(10 \mathrm{~cm}$, em média).

As coberturas mais grosseiras e espessas observadas na área encontram-se na depressão de Soutelo onde, por várias vezes, surgem taludes com 3 a 4 metros de enchimento. A dimensão dos maiores blocos (MPS), existentes nestes depósitos, aumenta à medida que caminhamos para leste, facto que é particularmente observável quando se efectuam trajectos de Serém para Soutelo (WSW-ENE).

Entre Jafafe e Soutelo (fig. 6, perfil CC'), o depósito de cobertura parece evidenciar um basculamento para leste, facto já apontado por CARVALHO (1951).

$O$ referido basculamento é denunciado pela posição dos blocos de maiores dimensões que definem niveis com pendor para leste, e pela diferença de cotas da base do depósito (50 metros a Oeste em Jafafe e 24 metros, a Este, no fundo da depressão de Soutelo). Também a inclinação do topo aplanado que se estabelece entre Jafafe e Soutelo é concordante com este basculamento.

\section{Conjunto II}

Neste conjunto incluem-se os depósitos de terraço e de vertente, provavelmente quaternários, uma vez que se correlacionam com a rede hidrográfica actual.

Fazem parte deste grupo, os terraços fluviais mais altos dos rios Caima e Vouga, assim como os depósitos aluviais actuais e os depósitos de vertente com expressão cartográfica que, no geral, cobrem pequenas áreas.

Em relação aos terraços fluviais dos rios Caima e Vouga podem-se definir três niveis para a área cartografada: un nivel inferior, até aos $15 \mathrm{~m}$, aproximadamente; um nível intermédio, entre os 20 e os 30 metros e um nível superior, entre os 40 e 50 metros. Trata-se de depósitos imaturos, de cor acinzentada (os mais baixos) ou amarelada escura (o nível superior), heterométricos e com seixos de aspecto lavado (fig. 5).

A litologia dos clastos é muito variada (quartzo, quartzito, gneisse, granito e xisto), assim como o seu grau de arredondamento. É visivel a imbricação dos clastos e, nalguns casos, uma abundante matriz fina

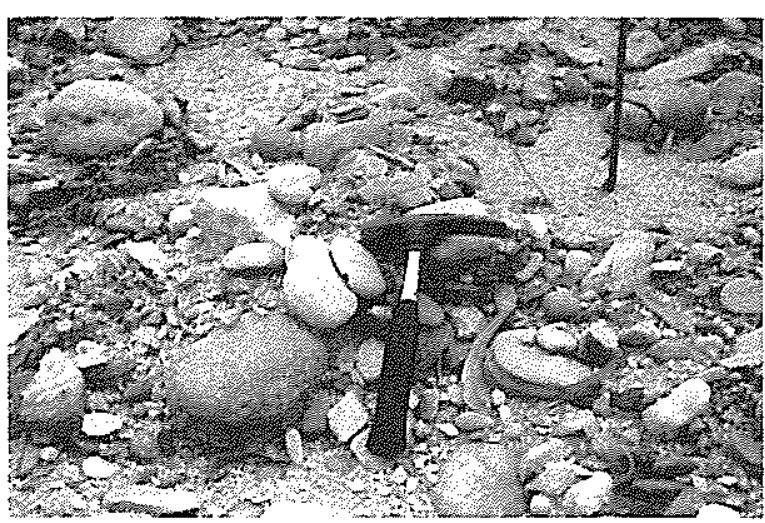

Fig. 5-Depósito fuuvial conglomerático do Vouga a norte de Soutelo.

Fig. 5 - Fluvial deposit of Vouga River north of Soutelo.

micácea ou argilosa de cor acinzentada. Nos terraços mais elevados nota-se que alguns clastos de quartzo e quartzito apresentam forte alteração química, com penetração irregular, conferindo aos clastos um aspecto cariado. Estes factos levam-nos a admitir que alguns do materiais que alimentaram estes terraços devem provir de depósitos mais antigos, nos quais se encontram clastos semelhantes e em avançado estado de alteração.

Os dois depósitos de vertente com representatividade cartográfica são formações avermelhadas de fraca espessura ( 2 a $3 \mathrm{~m}$ ), imaturas, heterométricas e com abundante matriz argilosa, que se encontram a cobrir o sopé das vertentes orientais e o fundo da bacia de Soutelo, assim como o sopé da vertente Oriental de Serém. Estas coberturas, que se distinguem muito bem das anteriores pela sua cor e matriz abundante, incorporam elementos dos diversos depósitos anteriores: seixos ou blocos arredondados de quartzo e quartzito e materiais mais recentes provenientes da alteração do substrato xistento, tais como argilas e palhetas de xisto.

\subsection{Interpretação geomorfológica.}

O sector estudado assemelha-se a um conjunto de teclas de piano, definindo-se vários blocos desnivelados, em que o compartimento mais abatido é ocupado pela faixa Ribeiro de Fráguas-Soutelo, que apresenta uma nítida diminuição de altitude para Sul (fig. 7).

$O$ relativo soerguimento dos blocos laterais (Plataforma de Albergaria e retalhos interiores aplanados) e o próprio graben central poderão ajudar a explicar o profundo encaixe que a rede hidrográfica apresenta e também, as frequentes vertentes abruptas destes vales, apesar de se tratar de cursos de água pouco extensos e de fraco caudal, se exceptuarmos o Caima e o Vouga. 


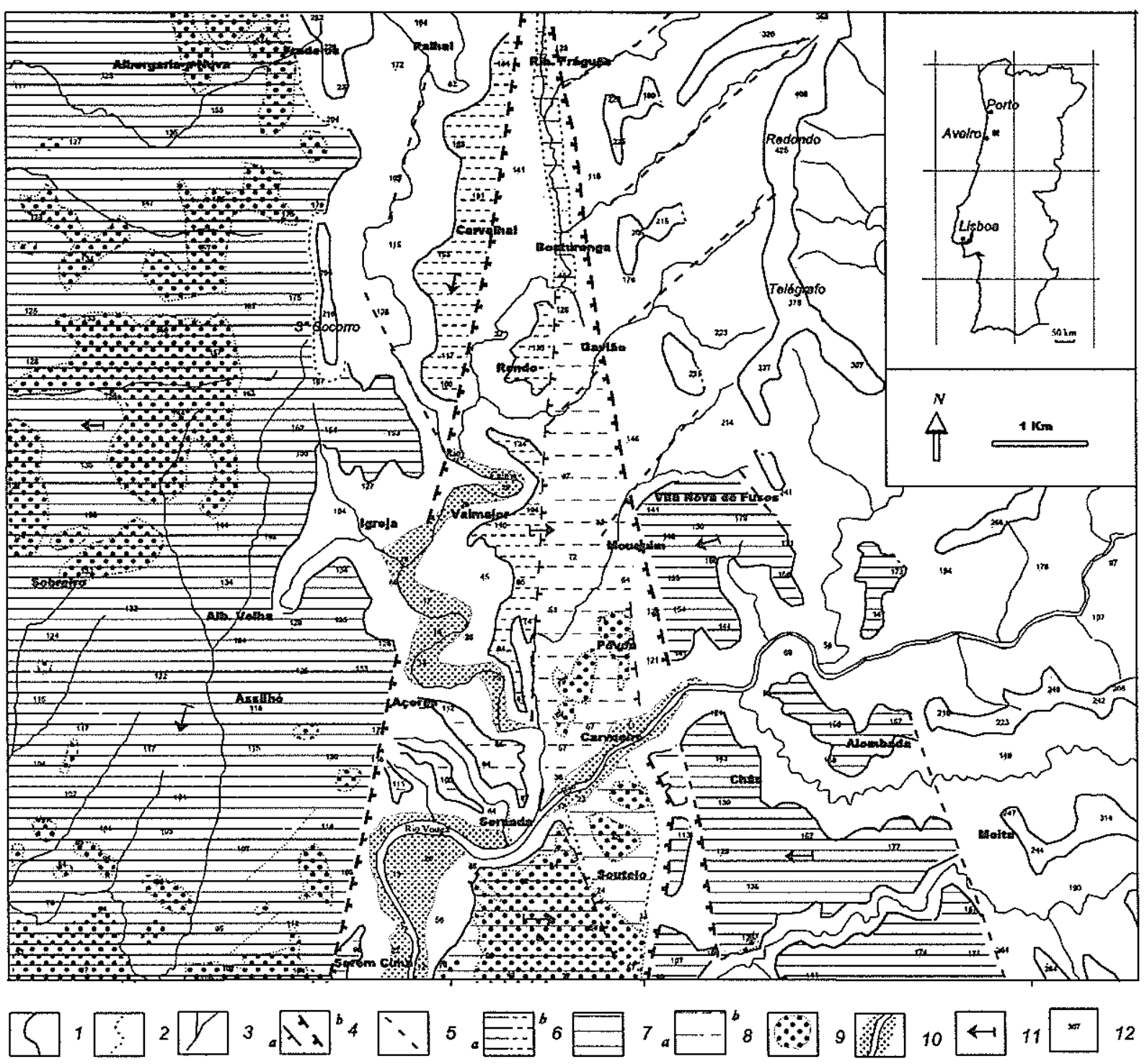

Fig. 7 - Interpretação geomorfológica da área estudada.

Legenda: 1 -topo de vertente; 2 - base de vertente; 3 -curso de água; 4 - escarpa de falha provável; a) com importante significado topográfico; b) com pouco significado topográfico; 5 - falha provável; 6 - nivel de aplanamento superior da plataforma litoral; a) bem conservado; b) mal conservado; 7 - nivel de aplanamento intermédio; 8 - nivel de aplanamento inferior; a) bem conservado; b) mal conservado; 9-coberturas antigas (Pliocénicas ou PlioQuaternárias); 10-terraços fluviais (Quaternário); 11 -basculamento; 12 - cota.

O corredor deprimido que se alarga para sul em forma de triângulo (fig. 7), deve corresponder a diferentes blocos abatidos, nos quais se definem pequenas depressões tectónicas (Telhadela, Mouquim, Carvoeiro, Valmaior e Soutelo).

Os terraços fluviais quaternários relativos a níveis mais elevados do Caima e do Vouga abundam neste
Fig. 7 - Geomorphologic interpretation of the area.

Legend: 1 -slope top; 2 -slope base; 3 -rivers; 4 -fault scarp (probably); a) strong topographic significance; b) weak topographic significance; 5 - fault; 6 -high level of littoral platform; a) well preserved; b) bad preserved; 7 -intermediate flat surface; 8 - low flat surface; a) well preserved; b) bad preserved; 9 -old covers (Pliocénic or Plio-Quaternary); 10 - fluvial sediments (Quaternary); 11 - inclination; 12 - altitude.

corredor deprimido, entre a Falha Porto-Tomar (tramo N/S entre Ribeira de Fráguas/Carvoeiro), e o acidente que parece existir entre Carvalhal e Açores, que define a fronteira ocidental do corredor. É neste corredor mais deprimido, favorável à deposição dos sedimentos, que se conservaram os enchimentos mais espessos, quer os que se referem à instalação da rede hidro- 


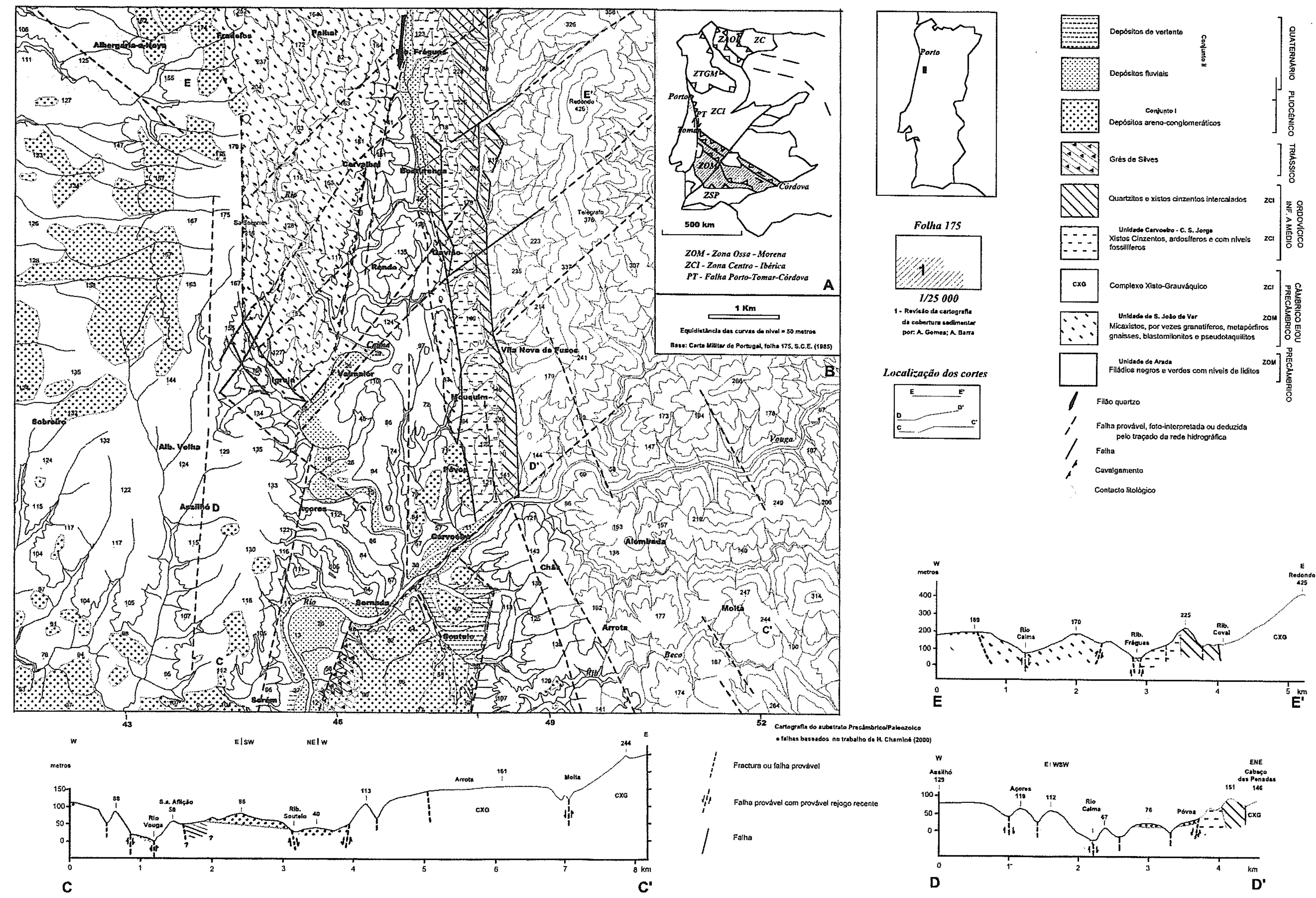

Fig. 6 - Esboço geológico da área estudada. Fig. 6-Geological map of the area. 
gráfica actual, quer os enchimentos anteriores a ela (Pliocénico? Plio-Quaternário?), materializados pelos depósitos aluviais presentes no fundo da Ribeira de Fráguas, na Póvoa e no trecho Jafafe/Soutelo.

O papel que as falhas tiveram na estruturação do relevo actual e no encaixe da rede hidrográfica é determinante. A Falha Porto-Tomar e a falha Carvalhal-Açores, desempenharam o papel principal na definição dos principais compartimentos abatidos e levantados e na condução preferencial do encaixe da rede fluvial, nomeadamente, dos cursos principais, Caima e Vouga.

Os acidentes NE/SW tiveram um papel importante na fragmentação da morfologia em pequenos blocos e na orientação da rede secundária, nomeadamente nas vertentes ocidentais da elevação Redondo-Telégrafo, no corredor deprimido e no próprio Vouga, entre as localidades do Carvoeiro e da Sernada.

É notório também que existe um desnivelamento entre as margens do Vouga, sendo mais elevada a margem norte e mais baixa a margem sul. Será este outro elemento indiciador da instalação do Vouga num acidente NE/SW conforme postula FERREIRA (1978)?

Talvez os acidentes tectónicos de direcção NNE/ /SSW e NNW/SSE, a norte de Valmaior possam explicar a preferência do Caima por este corredor e tenham facilitado a escavação do vale que neste trecho, se apresenta muito encaixado (entre Palhal e Valmaior). Para a confirmação destes acidentes concorre a existência de um desnivelamento entre os topos aplanados dos interflúvios neste troço.

A ser verdade este facto, implicaria a deslocação destes blocos em tempos fini ou pós-terciários. Estes movimentos poderão ser os factores responsáveis pelo soerguimento do sector oriental da plataforma litoral. Esta prolongar-se-ia para o interior, como atesta a presença de seixos rolados no seu topo entre Fradelos e a $\mathrm{Sr}^{\mathrm{a}}$ do Socorro, bem como, a continuidade dos aplanamentos que se estendem para Leste até aos retalhos aplanados de Vila Nova de Fusos, Alombada e Moita, afastados para o interior ( 4 a $6 \mathrm{~km}$, em média), em relação aos niveis aplanados correspondentes que se situam a oeste do corredor deprimido.

Os sectores aplanados a Oeste e a Leste do referido corredor, parecem-nos semelhantes em termos de génese, e a sua fragmentação deverá ser, por isso, posterior à elaboração da dita plataforma.

\section{CONCLUSÕES}

Em síntese, trata-se de um relevo fortemente contrastado que passou por uma fase prévia de aplanamento, provavelmente Pliocénica ou Pré-Pliocénica, materializada pela topo aplanado dos vários sectores.

Com base nas características dos depósitos que reconhecemos, no seu posicionamento e no enquadra- mento regional de formações semelhantes (Formação de Aguada e Formação da Gandra definidas por GRADE \& MOURA, 1980), pode-se definir-se pelo menos três momentos de deposição. Uma fase mais antiga (Pliocénica?), de condições mais biostáticas, em que o mar não estaria muito longe e que é representada pelos depósitos arenosos ou finos do conjunto I, que poderão ser do tipo fluvio-marinho, tal como afirmam Carvalho (1953a, b) e Ferreira (1978). Seguir-se-ia uma fase rexistática, de movimentação tectónica do relevo (Plio-Quaternário?), com o rejuvenescimento das escarpas que alimentariam a formação de leques aluviais representados pelos depósitos mais heterométricos e mais grosseiros do conjunto I, talvez semelhantes aos depósitos do tipo raña definidos por MARTIN-SERRANO (1988).

No Quaternário, dar-se-ia o encaixe da rede hidrográfica actual que seccionou as coberturas anteriores e que mobilizaria, para além de todo o material que transportava de locais a montante, os clastos que constituem estas coberturas. Ao mesmo tempo que se dava a incisão fluvial e o desmantelamento das vertentes, ter-se-iam feito sentir rejogos tectónicos nas falhas principais, que ajudaram a definir as linhas gerais da morfologia da área, nomeadamente os sectores soerguidos (A Plataforma de Albergaria) e deprimidos (o corredor deprimido Ribeira de Fráguas-Soutelo).

A movimentação tectónica recente é evidenciada pela compartimentação morfológica acima referida, pelos basculamentos para leste de algumas destas superficies aplanadas, assim como das suas coberturas, e o aparente deslocamento vertical que pelo menos, alguns depósitos do conjunto I parecem evidenciar.

$\mathrm{O}$ conhecimento geomorfológico desta área complexa ainda se encontra numa fase preliminar. Esperase no futuro completar as ideias apresentadas com novos dados que forçosamente nos farão repensar $\mathrm{e}$ produzir outros entendimentos.

\section{BIBLIOGRAFIA}

BArbosa, B. P. (1981) - Noticia Explicativa da folha 16-C (Vagos) da Carta Geológica de Portugal, na escala 1/50.000. Serviços Geológicos. de Portugal, Lisboa, 60 pp.

Barbosa, B. P. (1996) - Implicações da Estrutura Geológica de Aveiro-Vagos no Planeamento Regional e Urbano. Ed. Instituto Geológico e Mineiro, S. Mamede de Infesta, Portugal.

Barbosa, B. P. \& Reis, R. P. B. Pena dos, (1996) - Geometrias de enchimento, sistemas deposicionais e organização estratigráfica do Pliocénico continental da Bacia Terciária do Baixo Tejo (Portugal). Comunicações do Instituto Geológico e Mineiro, Lisboa, 82: 51-86.

CABral, J. (1995) - Neotectónica em Portugal Continental. Memórias Instituto Geológico e Mineiro, Lisboa, 31, $265 \mathrm{pp}$.

CAbral, J. \& Ribeiro, A. (1988) - Carta Neotectónica de Portugal Continental, escala 1/1.000.000. Serviços Geológicos. de Portugal / Departamento Geologia Faculdade Ciências Universidade de. Lisboa / Gabinete. Proteç̧ão. Segurança. Nuclear dos Serviços Geológicos. de Portugal (Ed.), Lisboa. 
CaRvalho, G. S. (1949) - Les dépôts des terraces et la paléogéographie du Pliocéne dans la bordure meso-cenozoique occidental du Portugal. Revista Faculdade Ciências Universidade de Coimbra, XVIH: $34-58$.

Carvalho, G. S. (1950)-Depósitos Pliocénicos de entre o Rio Vouga e o Rio Águeda (nota preliminar). Arquivo Distrito Aveiro, 16: 4-10.

Carvaluo, G. S. (1951) - Os Depósitos Detriticos e a Morfologia da Região de Aveiro. Memórias e Notícias, Publicaçöes do Museu e Laboratório de Mineralogia e. Geologia da Universidade de Coimbra, 31: 3-46.

CARVALHO, G. S. (1953a) - Les sediments pliocènique et la morphologie de la région entre Vouga et Mondego (Portugal). Memórias e Noticias, Publicações do Museu e Laboratório de Mineralogia e. Geologia da Universidade de Coimbra, 34: 3-18.

Carvalho, G. S. (1953b) - Quelques Résultats de l'Aplication de Méthodes Morphométriques aux Dépots Récents du Bassin du Vouga (Portugal). Association Internacionale Étude Quaternaire, Rome: 79-87.

Carval.ho, G. S. (1981) - Uma metodologia para análise dos depósitos do Quaternário. Arqueologia, Porto, 4: 50-63.

Chamine, H. (2000)-Estratigrafia e Estrutura da Faixa Metamórfica de Espinho-Albergaria-a-Velha (Zona de OssaMorena): Implicações Geodinâmicas. Tese de doutoramento (não publicado), Universidade do Porto, $520 \mathrm{pp}$. + anexos.

Cijado Teixeira, F., Pintieiro, L. M. (1998) - Contribuição para o estudo da evolução geológica da Ria de Aveiro e da Plataforma Continental adjacente. Actas do $V$ Congresso Nacional de Geologia (IGM), Lisboa, 84, I, C 43-47.

DAllmeyter, R. D., MARTtnez-Garcia, E. (1990) - Introduction to the Pre-Mesozoic Geology of Iberia. In Dallmeyer, R. D., Martinez-Garcia, E., Eds, Pre-Mesozoic Geology of Iberia. Springer Verlag. Berlin: 3-4.

DAvEAU, S. (1985) - Critères Geomorphologiques de Déformations Tectoniques Récents dans les Montagnes de Schistes de la
Cordilheira Central (Portugal). Bulletin de l'Association Française pour l'Étude du Quaternaire, Paris, 4: 229-238.

DAvenu, S. (1993) - Terraços fluviais e litorais. In O Quaternário em Portugal. Balanço e perspectivas. APEQ, Ed. Colibri, Lisboa: 17-28.

FerrelRA, A. B. (1978) - Planaltos e Montanhas do Norte da Beira - Estudo de Geomorfologia. Tese de doutoramento. Memória do Centro de Estudos Geográficos, 4, 374pp.

Ferreira, A. B. (199I) - Neotectonies in northern Portugal. A geomorphological approach. Zeit F. Geomorph, Berlin-Stutigart, Suppl. Bd. 82: 73-85.

Gonçalves, L. S. (1974)-Geologie und petrologie des gebietes von Oliveira de Azemeis un Albergaria-a-Velha (Portugal). Tese de doutoramento Frejen Universitat Berlin, $261 \mathrm{pp}$.

GonçALVES, L. S. (1981) - Excursão Geológica na região de Albergaria-a-Velha - Oliveira de Azcmeis. In: Livro-guia das Excursões da VI Reunião do Grupo Ossa-Morena, Laboratório de Mineralogia e. Geologia da Universidade de Coimbra, $14 \mathrm{pp}$.

Grade, J. \& MOURA, C. (1980) - Le Bassin Sedimentaire d'Aguada de Cima (Centre du Portugal). Boletim da Sociedade Geológico de Portigal, Lisboa. 22: 197-207.

Martin-Serrano, A. (1988) - Sobre la posición de la raña en el contexto morfodinámico de la Meseta. Planteamientos antigos y tendências actuais. Boletim. Geológico Minero España, 99: 855-870.

Silva, M. A. M., ANDRADE, A. S. (1998) - Sobre a profundidade do soco hercinico na região de Aveiro. Actas do $V$ Congresso Nacional de Geologia (IGM), Lisboa, 84, I, D40-D43.

TelXeira, C. (1979) - Plio-Plistocénico de Portugal. Comunicações Serviços Geológicos de Portugal, Lisboa, 65: 35-46.

TEIXEiRA, C. \& ZBYSZFEWSKI, G. (1954) - Contribution à l'étude du litoral pliocène au Portugal. Cong. Intern. Geol. C. R. de la dixnenvième session, Alger 1952. Section XIII.

TeixeirA, C. \& ZBY'SZEWSKI, G. (1976)-Carta Geológica de Portugal na escala 1/50 000. Noticia explicativa da folha 16-A (Aveiro), Serviços Geológicos de Portugal, Lisboa, 39 pp. 